\title{
Some integral type common fixed point theorems satisfying $\phi$-contractive conditions
}

\author{
Sunny Chauhan Erdal Karapinar
}

\begin{abstract}
In this manuscript, we obtain some common fixed point results of two pairs having the common limit range property in the setting of integral type contraction in the framework of symmetric (semi-metric) spaces. Moreover, we extend our results from two pairs of self-mappings to four finite families of self mappings to get common fixed points. Our results improve and extend a host of previously known results. Further, we establish some illustrative examples to show the validity of the main results.
\end{abstract}

\section{Introduction and preliminaries}

It is claimed that one of the dispensable tools of nonlinear analysis is the fixed point theory. The importance of fixed point theory arise from the application potential not only in the distinct branches of mathematics, but also various disciplines in quantitive sciences. The theory of fixed point is essential for the existence (and usually uniqueness) for solution of nonlinear differential equations, integrodifferential equations and integral equations in various abstract spaces. The renowned Banach fixed point theorem [6], the Banach contraction mapping principle, is the most impressed and earlier results in this direction, see e.g. $[8,10,12,13,24,31,32,33,35,38]$. Banach [6] proved that every contraction has a unique fixed point in the context of a complete metric space. This remarkable results has been generalized in various ways in distinct abstract spaces. Following

\footnotetext{
Received by the editors in September 2013.

Communicated by F. Bastin.

2010 Mathematics Subject Classification : 46T99,47H09, 47H10, 54H25. point.

Key words and phrases : common limit range property; weakly compatible mappings; fixed
} 
this paper, many authors have investigated the answer of the following question: Is it possible to guarantee the existence (and uniqueness) of a fixed point by replacing the weaker conditions on the set-up abstract space or on mappings. One of the remarkable answer of this question was given by Hicks and Rhoades [19]. In the mentioned paper, the authors obtained some nice results on common fixed point theorems in a semi-metric (symmetric) spaces. The notion of symmetric was obtained from metric by excluding the assumption of the subadditivity, that is, triangle inequality. Recently, Sintunavarat and Kumam [46] defined more refine notion, common limit range property. This property raze the requirement of completeness of the spaces closedness of the underlying subspaces. Very recently, Karapınar et al. [34] utilized the notion of common limit range property and established some common fixed point results for Lipschitz type mappings in context of symmetric spaces.

On the other hand, in 2002, Branciari [9] firstly established an integral type fixed point theorem for a self mapping which generalized Banach's contraction principle. Following this pioneer paper, a number of fixed point results for different integral type contraction condition have been reported by various authors. For more details, we refer the reader to e.g. [5, 4, 2, 7, 14, 37, 41, 42, 48, 49, 51].

In this manuscript, we obtain some common fixed point results of two pairs having the common limit range property in the setting of integral type $\phi$-contraction in the framework of symmetric (semi-metric) spaces. As an extension of presented result, we state some fixed point theorems for five mappings, six mappings and for four finite families of mappings in metric spaces by using the notion of the pairwise commuting mappings which is studied by Imdad et al. [23]. We conclude with examples that supports the usefulness of our results.

We recollect the essential definitions and basic results that will be needed later on.

For a non-empty set $X$, a real valued function $d: X \times X \rightarrow[0, \infty)$ is called symmetric if

$(\operatorname{sm} 1) d(x, y)=0 \Longleftrightarrow x=y$,

$(\operatorname{sm} 2) d(x, y)=d(y, x)$,

hold for all $x, y \in X$. For any $x \in X$, we define an open ball with respect to the corresponding topology, $\mathcal{T}_{d}$ on $X$, via $\mathcal{B}(x, \varepsilon)=\{y \in X: d(x, y)<\varepsilon\}$ where $x \in X$ and $\varepsilon>0$. If for each $\varepsilon>0$ and $x \in X$, the set $\mathcal{B}(x, \varepsilon)$ is a neighborhood of $x$ due to the topology $\mathcal{T}_{d}$, then a symmetric space $d$ is a semi-metric. We say that the sequence $\left\{x_{n}\right\}$ converges to a point $x \in X$, denoted as $x_{n} \rightarrow x$, if $\lim _{n \rightarrow \infty} d\left(x_{n}, x\right)=0$ with respect to the topology $\mathcal{T}_{d}$. For more details about the topological properties of symmetric space $(X, d)$ see e.g. [11].

In the proof of the existence and uniqueness of a fixed point, whether the space is Hausdorff has a critical role. On the other hand, the symmetric $d$ may not be continuous since symmetric space is not necessarily Hausdorff. To compensate the missing of the continuity of a symmetric $d$ and being Hausdorff of the related space, some additional axioms were suggested, see e.g. [4], [16], [19], [52]. 
Definition 1. Suppose that $(X, d)$ is a symmetric space where $X$ is a non-empty set. We suppose also that the sequences $\left\{x_{n}\right\},\left\{y_{n}\right\}$, and the points $x, y$ in $X$. Then,

$\left(W_{3}\right) \lim _{n \rightarrow \infty} d\left(x_{n}, x\right)=0$ and $\lim _{n \rightarrow \infty} d\left(x_{n}, y\right)=0$ imply $x=y[52]$.

$\left(W_{4}\right) \lim _{n \rightarrow \infty} d\left(x_{n}, x\right)=0$ and $\lim _{n \rightarrow \infty} d\left(x_{n}, y_{n}\right)=0$ imply $\lim _{n \rightarrow \infty} d\left(y_{n}, x\right)=0$ [52].

(HE) $\lim _{n \rightarrow \infty} d\left(x_{n}, x\right)=0$ and $\lim _{n \rightarrow \infty} d\left(y_{n}, x\right)=0$ imply $\lim _{n \rightarrow \infty} d\left(x_{n}, y_{n}\right)=0$ [4].

(1C) We say that a symmetric $d$ is 1 -continuous if $\lim _{n \rightarrow \infty} d\left(x_{n}, x\right)=0$ implies $\lim _{n \rightarrow \infty} d\left(x_{n}, y\right)=d(x, y)[16]$.

(CC) We say that a symmetric $d$ is continuous if $\lim _{n \rightarrow \infty} d\left(x_{n}, x\right)=0$ and $\lim _{n \rightarrow \infty} d\left(y_{n}, y\right)=0$ imply $\lim _{n \rightarrow \infty} d\left(x_{n}, y_{n}\right)=d(x, y)$ [16].

Here, it is observed that $(C C) \Longrightarrow(1 C),\left(W_{4}\right) \Longrightarrow\left(W_{3}\right)$, and $(1 C) \Longrightarrow\left(W_{3}\right)$. We notice that the converse of the implications above are not true (see e.g. [15]). As it is expected, (CC) implies all four conditions, $\left(W_{3}\right),\left(W_{4}\right),(H E)$ and $(1 C)$. Employing these axioms, several fixed point results have appeared in framework of symmetric spaces (see $[3,11,17,18,20,21,22,26,27])$.

Definition 2. Suppose that $(X, d)$ is a symmetric (semi-metric) space. Let $A$ and $S$ be two self mappings on $X$. We say that the pair $(A, S)$ is

1. commuting if $A S x=S A x$, for all $x \in X$,

2. weakly commuting if $d(A S x, S A x) \leq d(A x, S x)$, for all $x \in X$, [44],

3. compatible if $\lim _{n \rightarrow \infty} d\left(A S x_{n}, S A x_{n}\right)=0$,[29], under the assumption that $\left\{x_{n}\right\}$ is a sequence in $X$ such that $\lim _{n \rightarrow \infty} d\left(A x_{n}, t\right)=\lim _{n \rightarrow \infty} d\left(S x_{n}, t\right)=0$, for some $t \in X$,

4. non-compatible if there exists a sequence $\left\{x_{n}\right\}$ in $X$ for some $t \in X$ such that $\lim _{n \rightarrow \infty} d\left(A x_{n}, t\right)=\lim _{n \rightarrow \infty} d\left(S x_{n}, t\right)=0$ but $\lim _{n \rightarrow \infty} d\left(A S x_{n}, S A x_{n}\right)$ are either non-zero or non-existent,[40],

5. weakly compatible if self-mappings $A$ and $S$ commute at their coincidence points, $(A S u=S A u$ whenever $A u=S u$, for some $u \in X)$, [30].

For more details on systematic comparisons and illustrations of above described notions, we refer to Singh and Tomar [45] and Murthy [39].

Definition 3. [2] Suppose that $(X, d)$ is a symmetric (semi-metric) space. We said that a pair self-mappings $(A, S)$ on $X$, satisfy the property (E.A) if there exists a sequence $\left\{t_{n}\right\}$ and $t$ in $X$ such that

$$
\lim _{n \rightarrow \infty} d\left(A t_{n}, t\right)=\lim _{n \rightarrow \infty} d\left(S t_{n}, t\right)=0,
$$


Definition 4. [36] Suppose that $(X, d)$ is a symmetric (semi-metric) space and $A, S, B, T$ be self mappings on $X$. Pairs $(A, S)$ and $(B, T)$ of self mappings are said to satisfy the common property (E.A), if there exist two sequences $\left\{t_{n}\right\}$ and $\left\{s_{n}\right\}$ in $X$, and some $t \in X$ such that

$$
\lim _{n \rightarrow \infty} d\left(A t_{n}, t\right)=\lim _{n \rightarrow \infty} d\left(S t_{n}, t\right)=\lim _{n \rightarrow \infty} d\left(B s_{n}, t\right)=\lim _{n \rightarrow \infty} d\left(T s_{n}, t\right)=0 .
$$

Definition 5. [46] Suppose that $(X, d)$ is a symmetric (semi-metric) space and $A, S$ are two self mappings on $X$. We say that a pair $(A, S)$ is said to satisfy the common limit range of $S$ property, $\left(C L R_{S}\right)$ property, if there exists a sequence $\left\{t_{n}\right\}$ in $X$ such that

$$
\lim _{n \rightarrow \infty} d\left(A t_{n}, t\right)=\lim _{n \rightarrow \infty} d\left(S t_{n}, t\right)=0
$$

where $t \in S(X)$.

Hence it is assured that a pair $(A, S)$ satisfying the property (E.A) along with closedness of the subspace $S(X)$ always enjoys the $\left(C L R_{S}\right)$ property (see [21, Examples 2.16-2.17]).

Definition 6. [34] Suppose that $(X, d)$ is a symmetric (semi-metric) space and $A, S, B, T$ be self mappings on $X$. Pairs $(A, S)$ and $(B, T)$ of self mappings are said to satisfy the common limit in the range of $S$ and $T$ property, $\left(C L R_{S T}\right)$ property for short, if there exist two sequences $\left\{t_{n}\right\}$ and $\left\{s_{n}\right\}$ in $X$ such that

$$
\lim _{n \rightarrow \infty} d\left(A t_{n}, t\right)=\lim _{n \rightarrow \infty} d\left(S t_{n}, t\right)=\lim _{n \rightarrow \infty} d\left(B s_{n}, t\right)=\lim _{n \rightarrow \infty} d\left(T s_{n}, t\right)=0,
$$

where $t \in S(X) \cap T(X)$.

Therefore, common limit range property implies the common property (E.A). On the other hand, the converse of this implication is not true in general (see e.g. [34, Example 5]).

Definition 7. [23] Suppose that $(X, d)$ is a symmetric (semi-metric) space. Let $\left\{A_{i}\right\}_{i=1}^{m}$ and $\left\{S_{k}\right\}_{k=1}^{n}$ be Two families of self mappings on $X$. Two families $\left\{A_{i}\right\}_{i=1}^{m}$ and $\left\{S_{k}\right\}_{k=1}^{n}$ of self-mappings are called pairwise commuting if

1. $A_{j} A_{k}=A_{k} A_{j}$ for all $k, j \in\{1,2, \ldots, m\}$,

2. $S_{j} S_{k}=S_{k} S_{j}$ for all $k, j \in\{1,2, \ldots, n\}$,

3. $A_{j} S_{k}=S_{k} A_{j}$ for all $j \in\{1,2, \ldots, m\}$ and $k \in\{1,2, \ldots, n\}$.

\section{Main Results}

We start to this section by recalling the following auxiliary functions. Let $\Phi$ be the set of all functions $\phi$ such that $\phi: \mathbb{R}^{+} \rightarrow \mathbb{R}^{+}$with the conditions $0<\phi(t)<t$ for each $t>0$ and $\phi(0)=0$. Let $\Lambda$ be set of all functions $\varphi$ such that $\varphi: \mathbb{R}^{+} \rightarrow \mathbb{R}^{+}$ is a summable and non-negative Lebesgue-integrable mapping such that for all $\epsilon>0$

$$
\int_{0}^{\epsilon} \varphi(t) d t>0
$$

We, first, prove the following auxiliary result. 
Lemma 1. Let $X$ be a non-empty set and $(X, d)$ be a symmetric (semi-metric) space $(X, d)$ satisfying the condition $(C C)$. Suppose that self-mappings $A, B, S$ and $T$ satisfy the conditions below:

1. either the pair $(A, S)$ satisfies the $\left(C L R_{S}\right)$ property or the pair $(B, T)$ satisfies the $\left(C L R_{T}\right)$ property,

2. $A(X) \subset T(X)($ or $B(X) \subset S(X))$,

3. $T(X)($ or $S(X))$ is a closed subset of $X$,

4. $\left\{B y_{n}\right\}$ converges for every sequence $\left\{y_{n}\right\}$ in $X$ such that $\left\{T y_{n}\right\}$ converges (or $\left\{A x_{n}\right\}$ converges for every sequence $\left\{x_{n}\right\}$ in $X$ such that $\left\{S x_{n}\right\}$ converges),

5. there exists $\phi \in \Phi$ such that

$$
\int_{0}^{d(A x, B y)} \varphi(t) d t \leq \phi\left(\int_{0}^{a L(x, y)+(1-a) M(x, y)} \varphi(t) d t\right),
$$

for all $x, y \in X, 0 \leq a \leq 1$

where $\varphi \in \Lambda$ and

$$
\begin{aligned}
L(x, y) & =\max \{d(S x, T y), d(S x, B y), d(B y, T y)\} \\
M(x, y) & =\left(\max \left\{\begin{array}{c}
d^{2}(S x, T y), d(S x, B y) d(B y, T y), d(S x, T y) d(S x, B y), \\
d(S x, T y) d(B y, T y), d^{2}(B y, T y)
\end{array}\right\}\right)^{\frac{1}{2}} .
\end{aligned}
$$

Then, the pairs $(A, S)$ and $(B, T)$ share the $\left(C L R_{S T}\right)$ property.

Proof. Suppose that $(A, S)$ satisfies the $\left(C L R_{S}\right)$ property with respect to mapping $S$, that is, there exists a sequence $\left\{x_{n}\right\}$ in $X$ and $t \in S(X)$ such that

$$
\lim _{n \rightarrow \infty} d\left(S x_{n}, t\right)=\lim _{n \rightarrow \infty} d\left(A x_{n}, t\right)=0 .
$$

Regarding the condition (CC), we obtain that $\lim _{n \rightarrow \infty} d\left(A x_{n}, S x_{n}\right)=0$. So, for any sequence $\left\{x_{n}\right\}$ in $X$, there exists another sequence $\left\{y_{n}\right\}$ in $X$ with $A x_{n}=T y_{n}$, owing to the fact that $A(X) \subset T(X)$. Hence, $t \in S(X) \cap T(X)$ since $T(X)$ is closed. Consequently, we derive that

$$
\lim _{n \rightarrow \infty} d\left(A x_{n}, t\right)=\lim _{n \rightarrow \infty} d\left(S x_{n}, t\right)=\lim _{n \rightarrow \infty} d\left(T y_{n}, t\right)=t \in S(X) \cap T(X) .
$$

By (4), the sequence $\left\{B y_{n}\right\}$ converges. Let the sequence $\left\{B y_{n}\right\}$ converges to $z(\neq t)$ as $n \rightarrow \infty$. Now we need to show that $z=t$.

Again by $(C C)$, we have $\lim _{n \rightarrow \infty} d\left(S x_{n}, B y_{n}\right)=d(t, z)$ and $\lim _{n \rightarrow \infty} d\left(A x_{n}, B y_{n}\right)=$ $d(t, z)$. On using inequality (2.2) with $x=x_{n}, y=y_{n}$, we have

$$
\int_{0}^{d\left(A x_{n}, B y_{n}\right)} \varphi(t) d t \leq \phi\left(\int_{0}^{a L\left(x_{n}, y_{n}\right)+(1-a) M\left(x_{n}, y_{n}\right)} \varphi(t) d t\right)
$$


where

$$
\begin{aligned}
L\left(x_{n}, y_{n}\right) & =\max \left\{d\left(S x_{n}, T y_{n}\right), d\left(S x_{n}, B y_{n}\right), d\left(B y_{n}, T y_{n}\right)\right\} \\
& =\max \left\{d\left(S x_{n}, A x_{n}\right), d\left(S x_{n}, B y_{n}\right), d\left(B y_{n}, A x_{n}\right)\right\}
\end{aligned}
$$

and

$$
\begin{aligned}
M\left(x_{n}, y_{n}\right) & =\left(\max \left\{\begin{array}{c}
d^{2}\left(S x_{n}, T y_{n}\right), d\left(S x_{n}, B y_{n}\right) d\left(B y_{n}, T y_{n}\right), \\
d\left(S x_{n}, T y_{n}\right) d\left(S x_{n}, B y_{n}\right), d\left(S x_{n}, T y_{n}\right) d\left(B y_{n}, T y_{n}\right), \\
d^{2}\left(B y_{n}, T y_{n}\right)
\end{array}\right\}\right)^{\frac{1}{2}} \\
& =\left(\max \left\{\begin{array}{c}
d^{2}\left(S x_{n}, A x_{n}\right), d\left(S x_{n}, B y_{n}\right) d\left(B y_{n}, A x_{n}\right), \\
d\left(S x_{n}, A x_{n}\right) d\left(S x_{n}, B y_{n}\right), d\left(S x_{n}, A x_{n}\right) d\left(B y_{n}, A x_{n}\right), \\
d^{2}\left(B y_{n}, A x_{n}\right)
\end{array}\right\}\right)^{\frac{1}{2}} .
\end{aligned}
$$

Taking limit as $n \rightarrow \infty$ in (2.3), we get

$$
\begin{aligned}
\lim _{n \rightarrow \infty} \int_{0}^{d\left(A x_{n}, B y_{n}\right)} \varphi(t) d t & \leq \lim _{n \rightarrow \infty} \phi\left(\int_{0}^{a L\left(x_{n}, y_{n}\right)+(1-a) M\left(x_{n}, y_{n}\right)} \varphi(t) d t\right) \\
\int_{0}^{d(t, z)} \varphi(t) d t & \leq \phi\left(\lim _{n \rightarrow \infty} \int_{0}^{a L\left(x_{n}, y_{n}\right)+(1-a) M\left(x_{n}, y_{n}\right)} \varphi(t) d t\right),
\end{aligned}
$$

where

$$
\begin{aligned}
\lim _{n \rightarrow \infty} L\left(x_{n}, y_{n}\right) & =\lim _{n \rightarrow \infty} \max \left\{d\left(S x_{n}, A x_{n}\right), d\left(S x_{n}, B y_{n}\right), d\left(B y_{n}, A x_{n}\right)\right\} \\
& =\max \{0, d(t, z), d(z, t)\} \\
& =d(t, z),
\end{aligned}
$$

and

$$
\begin{aligned}
\lim _{n \rightarrow \infty} M\left(x_{n}, y_{n}\right) & =\left(\lim _{n \rightarrow \infty} \max \left\{\begin{array}{c}
d^{2}\left(S x_{n}, A x_{n}\right), d\left(S x_{n}, B y_{n}\right) d\left(B y_{n}, A x_{n}\right), \\
d\left(S x_{n}, A x_{n}\right) d\left(S x_{n}, B y_{n}\right), \\
d\left(S x_{n}, A x_{n}\right) d\left(B y_{n}, A x_{n}\right), d^{2}\left(B y_{n}, A x_{n}\right)
\end{array}\right\}\right)^{\frac{1}{2}} \\
& =\left(\max \left\{0, d(t, z) d(z, t), 0,0, d^{2}(z, t)\right\}\right)^{\frac{1}{2}} \\
& =\left(d^{2}(t, z)\right)^{\frac{1}{2}} \\
& =d(t, z) .
\end{aligned}
$$

Hence (2.4) implies

$$
\begin{aligned}
\int_{0}^{d(t, z)} \varphi(t) d t & \leq \phi\left(\int_{0}^{a d(t, z)+(1-a) d(t, z)} \varphi(t) d t\right) \\
& =\phi\left(\int_{0}^{d(t, z)} \varphi(t) d t\right) \\
& <\int_{0}^{d(t, z)} \varphi(t) d t
\end{aligned}
$$


which is a contradiction. Therefore, $\int_{0}^{d(t, z)} \varphi(t) d t=0$. In view of (2.1), we obtain $d(t, z)=0$, i.e., $B y_{n} \rightarrow t$ as $n \rightarrow \infty$. Hence the pairs $(A, S)$ and $(B, T)$ satisfy the $\left(C L R_{S T}\right)$ property. This completes the proof.

Now, we state the first theorem of this manuscript as follows.

Theorem 1. Let $(X, d)$ be a symmetric space. Suppose that the self-mappings $A, B, S$ and $T$ defined on $X$ satisfying the hypothesis (4) of Lemma 1 with (1C) and (HE). Each pair $(A, S)$ and $(B, T)$ have a coincidence point each if the pairs $(A, S)$ and $(B, T)$ satisfy the $\left(C L R_{S T}\right)$ property. Furthermore, we conclude that the self-mappings $A, B, S$ and $T$ have a unique common fixed point if $(A, S)$ and $(B, T)$ are weakly compatible.

Proof. Let $(A, S)$ and $(B, T)$ be pairs of self-mappings on $X$ and satisfy the $\left(C L R_{S T}\right)$ property. Thus, we have sequences $\left\{x_{n}\right\}$ and $\left\{y_{n}\right\}$ in $X$ such that

$$
\lim _{n \rightarrow \infty} d\left(A x_{n}, t\right)=\lim _{n \rightarrow \infty} d\left(S x_{n}, t\right)=\lim _{n \rightarrow \infty} d\left(T y_{n}, t\right)=\lim _{n \rightarrow \infty} d\left(B y_{n}, t\right)=0,
$$

where $t \in S(X) \cap T(X)$. Since $t \in S(X)$, there exists a point $u \in X$ such that $S u=t$. Hence, we derive that

$$
\lim _{n \rightarrow \infty} d\left(A x_{n}, S u\right)=\lim _{n \rightarrow \infty} d\left(S x_{n}, S u\right)=\lim _{n \rightarrow \infty} d\left(T y_{n}, S u\right)=\lim _{n \rightarrow \infty} d\left(B y_{n}, S u\right)=0,
$$

Now we assert that $A u=t$. Suppose that $A u \neq t$. So, by using (2.2) with $x=u$ and $y=y_{n}$, we get

$$
\int_{0}^{d\left(A u, B y_{n}\right)} \varphi(t) d t \leq \phi\left(\int_{0}^{a L\left(u, y_{n}\right)+(1-a) M\left(u, y_{n}\right)} \varphi(t) d t\right),
$$

where

$$
L\left(u, y_{n}\right)=\max \left\{d\left(S u, T y_{n}\right), d\left(S u, B y_{n}\right), d\left(B y_{n}, T y_{n}\right)\right\}
$$

and

$$
M\left(u, y_{n}\right)=\left(\max \left\{\begin{array}{c}
d^{2}\left(S u, T y_{n}\right), d\left(S u, B y_{n}\right) d\left(B y_{n}, T y_{n}\right), \\
d\left(S u, T y_{n}\right) d\left(S u, B y_{n}\right), \\
d\left(S u, T y_{n}\right) d\left(B y_{n}, T y_{n}\right), d^{2}\left(B y_{n}, T y_{n}\right)
\end{array}\right\}\right)^{\frac{1}{2}}
$$

Regarding (1C) and (HE) together with letting $n \rightarrow \infty$ in (2.5), we obtain that

$$
\begin{aligned}
\int_{0}^{d(A u, t)} \varphi(t) d t & \leq \lim _{n \rightarrow \infty} \phi\left(\int_{0}^{a L\left(u, y_{n}\right)+(1-a) M\left(u, y_{n}\right)} \varphi(t) d t\right) \\
& =\phi\left(\lim _{n \rightarrow \infty} \int_{0}^{a L\left(u, y_{n}\right)+(1-a) M\left(u, y_{n}\right)} \varphi(t) d t\right)
\end{aligned}
$$

where

$$
\begin{aligned}
\lim _{n \rightarrow \infty} L\left(u, y_{n}\right) & =\lim _{n \rightarrow \infty} \max \left\{d\left(S u, T y_{n}\right), d\left(S u, B y_{n}\right), d\left(B y_{n}, T y_{n}\right)\right\} \\
& =0
\end{aligned}
$$


and

$$
\begin{aligned}
\lim _{n \rightarrow \infty} M\left(x_{n}, y_{n}\right) & =\left(\max \left\{\begin{array}{c}
d^{2}\left(S u, T y_{n}\right), d\left(S u, B y_{n}\right) d\left(B y_{n}, T y_{n}\right), \\
d\left(S u, T y_{n}\right) d\left(S u, B y_{n}\right), \\
d\left(S u, T y_{n}\right) d\left(B y_{n}, T y_{n}\right), d^{2}\left(B y_{n}, T y_{n}\right)
\end{array}\right\}\right)^{\frac{1}{2}} \\
& =0 .
\end{aligned}
$$

From (2.6), we conclude that

$$
\begin{aligned}
\int_{0}^{d(A u, t)} \varphi(t) d t & \leq \phi\left(\int_{0}^{a .0+(1-a) 0} \varphi(t) d t\right) \\
& =0,
\end{aligned}
$$

a contradiction. Hence, by taking (2.1) into account, we find $d(A u, t)=0$ and so $t=A u=S u$.

Since $t \in T(X)$, there exists a point $v \in X$ such that $T v=t$. We shall show that $B v=T v$. Suppose that $B v \neq T v$. Then, by using the inequality (2.2) with $x=u, y=v$, we get

$$
\begin{aligned}
\int_{0}^{d(t, B v)} \varphi(t) d t & =\int_{0}^{d(A u, B v)} \varphi(t) d t \\
& \leq \phi\left(\int_{0}^{a L(u, v)+(1-a) M(u, v)} \varphi(t) d t\right)
\end{aligned}
$$

where

$$
\begin{aligned}
L(u, v) & =\max \{d(S u, T v), d(S u, B v), d(B v, T v)\} \\
& =\max \{d(t, t), d(t, B v), d(B v, t)\} \\
& =d(t, B v)
\end{aligned}
$$

and

$$
\begin{aligned}
M(u, v) & =\left(\max \left\{\begin{array}{c}
d^{2}(S u, T v), d(S u, B v) d(B v, T v), d(S u, T v) d(S u, B v), \\
d(S u, T v) d(B v, T v), d^{2}(B v, T v)
\end{array}\right\}\right)^{\frac{1}{2}} \\
& =\left(\max \left\{\begin{array}{c}
d^{2}(t, t), d(t, B v) d(B v, t), d(t, t) d(t, B v), \\
d(t, t) d(B v, t), d^{2}(B v, t)
\end{array}\right\}\right)^{\frac{1}{2}} \\
& =\left(d^{2}(t, B v)\right)^{\frac{1}{2}} \\
& =d(t, B v) .
\end{aligned}
$$

Hence (2.7) implies

$$
\begin{aligned}
\int_{0}^{d(t, B v)} \varphi(t) d t & \leq \phi\left(\int_{0}^{a d(t, B v)+(1-a) d(t, B v)} \varphi(t) d t\right) \\
& =\phi\left(\int_{0}^{d(t, B v)} \varphi(t) d t\right) \\
& <\int_{0}^{d(t, B v)} \varphi(t) d t
\end{aligned}
$$


a contradiction. Thus, we have $\int_{0}^{d(t, B v)} \varphi(t) d t=0$. On account of (2.1), we derive that $B v=T v=t$.

We derive that $A t=A S u=S A u=S t$ owing to the fact that $A u=S u$ and the self mappings $A$ and $S$ are weakly compatible. At this point, we shall prove that $t$ is a common fixed of the self-mappings $A$ and $S$. We assume that $A t \neq t$. By using the inequality (2.2) with $x=t, y=v$, we have

$$
\begin{aligned}
\int_{0}^{d(A t, t)} \varphi(t) d t & =\int_{0}^{d(A t, B v)} \varphi(t) d t \\
& \leq \phi\left(\int_{0}^{a L(t, v)+(1-a) M(t, v)} \varphi(t) d t\right),
\end{aligned}
$$

where

$$
\begin{aligned}
L(t, v) & =\max \{d(S t, T v), d(S t, B v), d(B v, T v)\} \\
& =\max \{d(A t, t), d(A t, t), d(t, t)\} \\
& =d(A t, t)
\end{aligned}
$$

and

$$
\begin{aligned}
& M(t, v)=\left(\max \left\{\begin{array}{c}
d^{2}(S t, T v), d(S t, B v) d(B v, T v), d(S t, T v) d(S t, B v), \\
d(S t, T v) d(B v, T v), d^{2}(B v, T v)
\end{array}\right\}\right)^{\frac{1}{2}} \\
& =\left(\max \left\{\begin{array}{c}
d^{2}(A t, t), d(A t, t) d(t, t), d(A t, t) d(A t, t), \\
d(A t, t) d(t, t), d^{2}(t, t)
\end{array}\right\}\right)^{\frac{1}{2}} \\
& =\left(d^{2}(A t, t)\right)^{\frac{1}{2}} \\
& =d(A t, t) \text {. }
\end{aligned}
$$

From (2.8), we get

$$
\begin{aligned}
\int_{0}^{d(A t, t)} \varphi(t) d t & \leq \phi\left(\int_{0}^{a d(A t, t)+(1-a) d(A t, t)} \varphi(t) d t\right) \\
& =\phi\left(\int_{0}^{d(A t, t)} \varphi(t) d t\right) \\
& <\int_{0}^{d(A t, t)} \varphi(t) d t
\end{aligned}
$$

a contradiction. Consequently, we have $A t=t=S t$, that is, $t$ is a common fixed point of the pair $(A, S)$.

Since the pair $(B, T)$ is weakly compatible, the equality yields that $B t=B T w=$ $T B w=T t$. If not, then using inequality (2.2) with $x=u, y=t$, we have

$$
\begin{aligned}
\int_{0}^{d(t, B t)} \varphi(t) d t & =\int_{0}^{d(A u, B t)} \varphi(t) d t \\
& \leq \phi\left(\int_{0}^{a L(u, t)+(1-a) M(u, t)} \varphi(t) d t\right),
\end{aligned}
$$


where

$$
\begin{aligned}
L(u, t) & =\max \{d(S u, T t), d(S u, B t), d(B t, T t)\} \\
& =\max \{d(t, B t), d(t, B t), d(B t, B t)\} \\
& =d(t, B v)
\end{aligned}
$$

and

$$
\begin{aligned}
M(u, t) & =\left(\max \left\{\begin{array}{c}
d^{2}(S u, T t), d(S u, B t) d(B t, T t), d(S u, T t) d(S u, B t), \\
d(S u, T t) d(B t, T t), d^{2}(B t, T t)
\end{array}\right\}\right)^{\frac{1}{2}} \\
& =\left(\max \left\{\begin{array}{c}
d^{2}(t, B t), d(t, B t) d(B t, B t), d(t, B t) d(t, B t), \\
d(t, B t) d(B t, B t), d^{2}(B t, B t)
\end{array}\right\}\right)^{\frac{1}{2}} \\
& =\left(d^{2}(t, B t)\right)^{\frac{1}{2}} \\
& =d(t, B t) .
\end{aligned}
$$

Hence (2.9) implies

$$
\begin{aligned}
\int_{0}^{d(t, B t)} \varphi(t) d t & \leq \phi\left(\int_{0}^{a d(t, B t)+(1-a) d(t, B t)} \varphi(t) d t\right) \\
& =\phi\left(\int_{0}^{d(t, B t)} \varphi(t) d t\right) \\
& <\int_{0}^{d(t, B t)} \varphi(t) d t
\end{aligned}
$$

a contradiction. Therefore, $B t=t=T t$ which shows that $t$ is a common fixed point of the pair $(B, T)$. Hence $t$ is a common fixed point of the self-mappings $A, S, B, T$.

We use the method of reductio the absurdum to prove the uniqueness. Suppose, on the contrary, that there is another common fixed point $t^{\prime}(\neq t)$ of the self-mappings $A, B, S, T$. Hence, by replacing $x=t$ and $y=t^{\prime}$ in the inequality (2.2), we observe that

$$
\begin{aligned}
\int_{0}^{d\left(t, t^{\prime}\right)} \varphi(t) d t & =\int_{0}^{d\left(A t, B t^{\prime}\right)} \varphi(t) d t \\
& \leq \phi\left(\int_{0}^{a L\left(t, t^{\prime}\right)+(1-a) M\left(t, t^{\prime}\right)} \varphi(t) d t\right),
\end{aligned}
$$

where

$$
\begin{aligned}
L\left(t, t^{\prime}\right) & =\max \left\{d\left(S t, T t^{\prime}\right), d\left(S t, B t^{\prime}\right), d\left(B t^{\prime}, T t^{\prime}\right)\right\} \\
& =\max \left\{d\left(t, t^{\prime}\right), d\left(t, t^{\prime}\right), d\left(t^{\prime}, t^{\prime}\right)\right\} \\
& =d\left(t, t^{\prime}\right)
\end{aligned}
$$


and

$$
\begin{aligned}
M\left(t, t^{\prime}\right) & =\left(\max \left\{\begin{array}{c}
d^{2}\left(S t, T t^{\prime}\right), d\left(S t, B t^{\prime}\right) d\left(B t^{\prime}, T t^{\prime}\right), d\left(S t, T t^{\prime}\right) d\left(S t, B t^{\prime}\right), \\
d\left(S t, T t^{\prime}\right) d\left(B t^{\prime}, T t^{\prime}\right), d^{2}\left(B t^{\prime}, T t^{\prime}\right)
\end{array}\right\}\right)^{\frac{1}{2}} \\
& =\left(\max \left\{\begin{array}{c}
d^{2}\left(t, t^{\prime}\right), d\left(t, t^{\prime}\right) d\left(t^{\prime}, t^{\prime}\right), d\left(t, t^{\prime}\right) d\left(t, t^{\prime}\right), \\
d\left(t, t^{\prime}\right) d\left(t^{\prime}, t^{\prime}\right), d^{2}\left(t^{\prime}, t^{\prime}\right)
\end{array}\right\}\right) \\
& =\left(d^{2}\left(t, t^{\prime}\right)\right)^{\frac{1}{2}} \\
& =d\left(t, t^{\prime}\right) .
\end{aligned}
$$

As a result, (2.8) implies that

$$
\begin{aligned}
\int_{0}^{d\left(t, t^{\prime}\right)} \varphi(t) d t & \leq \phi\left(\int_{0}^{a d\left(t, t^{\prime}\right)+(1-a) d\left(t, t^{\prime}\right)} \varphi(t) d t\right) \\
& =\phi\left(\int_{0}^{d\left(t, t^{\prime}\right)} \varphi(t) d t\right) \\
& <\int_{0}^{d\left(t, t^{\prime}\right)} \varphi(t) d t
\end{aligned}
$$

Hence, we obtain that $t=t^{\prime}$, a contradiction.

Remark 1. Theorem 1 improves the corresponding results contained in Tiwari et al. [48, Theorem 3.1] as completeness (or closedness) of the underlying subspaces are not required.

Now, we give an illustrative example.

Example 1. Let $X=[2,11)$ and the symmetric (semi-metric) $d$ be defined as $d(x, y)=e^{|x-y|}-1$ for all $x, y \in X$. We also assume that $(1 C)$ and $(H E)$ are satisfied. Define the self mappings $A, B, S$ and $T$ and $\varphi: \mathbb{R}^{+} \rightarrow \mathbb{R}^{+}$by

$$
\begin{gathered}
A x=\left\{\begin{array}{ll}
2, & \text { if } x \in\{2\} \cup(7,11) ; \\
8, & \text { if } 2<x \leq 7 .
\end{array} \quad B x= \begin{cases}2, & \text { if } x \in\{2\} \cup(7,11) ; \\
9, & \text { if } 2<x \leq 7 .\end{cases} \right. \\
S x=\left\{\begin{array}{ll}
2, & \text { if } x=2 ; \\
6, & \text { if } 2<x \leq 7 ; \\
x-5, & \text { if } 7<x<11 .
\end{array} \quad \text { T } x= \begin{cases}2, & \text { if } x=2 ; \\
9, & \text { if } 2<x \leq 7 ; \\
\frac{x+1}{4}, & \text { if } 7<x<11 .\end{cases} \right.
\end{gathered}
$$

Then we have $A(X)=\{2,8\} \nsubseteq[2,3) \cup\{9\}=T(X)$ and $B(X)=\{2,9\} \nsubseteq$ $[2,7)=S(X)$. Also define

$$
\varphi(t)= \begin{cases}(\ln (1+t))^{\frac{1}{\ln (1+t)}-2}\left[\frac{1-\ln (\ln (1+t))}{1+t}\right], & \text { if } t>0 \\ 0, & \text { if } t=0\end{cases}
$$


If we choose two sequences as $\left\{x_{n}\right\}=\left\{7+\frac{1}{n}\right\}_{n \in \mathbb{N}^{\prime}}\left\{y_{n}\right\}=\{2\}$ (or $\left\{x_{n}\right\}=$ $\left.\{2\},\left\{y_{n}\right\}=\left\{7+\frac{1}{n}\right\}_{n \in \mathbb{N}}\right)$, then pairs $(A, S)$ and $(B, T)$ satisfy the $\left(C L R_{S T}\right)$ property:

$$
\lim _{n \rightarrow \infty} d\left(A x_{n}, 2\right)=\lim _{n \rightarrow \infty} d\left(S x_{n}, 2\right)=\lim _{n \rightarrow \infty} d\left(B y_{n}, 2\right)=\lim _{n \rightarrow \infty} d\left(T y_{n}, 2\right)=0,
$$

where $2 \in S(X) \cap T(X)$. By elementary calculation, we derive the inequality (2.2) easily. Hence, we can conclude that all the conditions of Theorem 1 holds. Moreover, we observe that 2 is a unique common fixed point of the self-mappings $A, S, B, T$. Notice that the self-mappings $A, B, S, T$ are discontinuous at point 2 . We also emphasize that the subspaces $S(X)$ and $T(X)$ are not closed subspaces of $X$. Consequently, the main result of Tiwari et al. [48, Theorem 3.1] is not applicable here.

Corollary 1. Let $(X, d)$ be a symmetric space and $A, B, S, T$ be a self-mappings on $X$ satisfying all the hypotheses of Lemma 1 with (CC), then the self-mappings $A, B, S, T$ have a unique common fixed point if $(A, S)$ and $(B, T)$ are weakly compatible.

Proof. Owing to Lemma 1, it follows that $(A, S)$ and $(B, T)$ satisfy the $\left(C L R_{S T}\right)$ property. Consequently, the conditions of Theorem 1 are satisfied, and the selfmappings $A, B, S, T$ have a unique common fixed point under the assumption that both the pairs of selfmappings $(A, S)$ and $(B, T)$ are weakly compatible.

It is pointed out that Example 1 cannot be obtained using Corollary 1, since conditions (2) and (3) of Lemma 1 are not fulfilled. We present another example, showing the situation where the conclusion can be reached using Corollary 1.

Example 2. Let $X=[2,24)$ and the symmetric (semi-metric) $d$ be defined as $d(x, y)=e^{|x-y|}-1$ for all $x, y \in X$. Assume also that the condition $(C C)$ is satisfied. Define $\varphi: \mathbb{R}^{+} \rightarrow \mathbb{R}^{+}$as in Example 1 and the self mappings $A, B, S$ and $T$ by

$$
\begin{gathered}
A x=\left\{\begin{array}{ll}
2, & \text { if } x \in\{2\} \cup(9,24) ; \\
16, & \text { if } 2<x \leq 9 .
\end{array} \quad B x= \begin{cases}2, & \text { if } x \in\{2\} \cup(9,24) ; \\
4, & \text { if } 2<x \leq 9 .\end{cases} \right. \\
S x=\left\{\begin{array}{ll}
2, & \text { if } x=2 ; \\
5, & \text { if } 2<x \leq 9 ; \\
\frac{x+1}{5}, & \text { if } 9<x<24 .
\end{array} \quad \text { if } x= \begin{cases}2, & \text { if } x=2 ; \\
17, & \text { if } 2<x \leq 9 ; \\
x-7, & \text { if } 9<x<24 .\end{cases} \right.
\end{gathered}
$$

Then we observe that $A(X)=\{2,16\} \subset[2,17]=T(X)$ and $B(X)=\{2,4\} \subset$ $[2,5]=S(X)$. It is evident that the pairs $(A, S)$ and $(B, T)$ satisfy the $\left(C L R_{S T}\right)$ property Indeed, we have $\left\{x_{n}=9+\frac{1}{n}\right\}_{n \in \mathbb{N}},\left\{y_{n}=2\right\}$ or $\left\{x_{n}=2\right\}$, $\left\{y_{n}=9+\frac{1}{n}\right\}_{n \in \mathbb{N}}$, i.e.,

$$
\lim _{n \rightarrow \infty} d\left(A x_{n}, 2\right)=\lim _{n \rightarrow \infty} d\left(S x_{n}, 2\right)=\lim _{n \rightarrow \infty} d\left(B y_{n}, 2\right)=\lim _{n \rightarrow \infty} d\left(T y_{n}, 2\right)=0,
$$

where $2 \in S(X) \cap T(X)$. Also all the conditions of Corollary 1 can be easily verified. It is noted here that 2 is a unique common fixed point of $(A, S)$ and $(B, T)$. 
Notice that this example is not applicable for Theorem 1 since $S(X), T(X)$ are closed subsets of $X$ which demonstrates the situational utility of Corollary 1 over Theorem 1.

The conclusion of Lemma 1, Theorem 1 and Corollary 1 remains true for a suitable choice of $a=1$.

Corollary 2. Suppose that $(X, d)$ is a symmetric space and self-mappings $A, B, S, T$ on $X$ satisfy the hypothesis (4) of Lemma 1 with (1C) and (HE). Assume that

1. the pairs of self-mappings $(A, S)$ and $(B, T)$ satisfies the $\left(C L R_{S T}\right)$ property,

2. there exists $\phi \in \Phi$ such that

$$
\int_{0}^{d(A x, B y)} \varphi(t) d t \leq \phi\left(\int_{0}^{L(x, y)} \varphi(t) d t\right),
$$

where $\varphi \in \Lambda$ and $L(x, y)=\max \{d(S x, T y), d(S x, B y), d(B y, T y)\}$, for all $x, y \in X$.

Then, both pairs $(A, S)$ and $(B, T)$ have a coincidence point. Furthermore, if the pairs of $(A, S)$ and $(B, T)$ are weakly compatible, then the self-mappings $A, B, S, T$ have a unique common fixed point.

On taking $\varphi(t)=1$ in Theorem 1 , we have the following natural result:

Corollary 3. Suppose that $(X, d)$ is a symmetric space and self-mappings $A, B, S, T$ on $X$ satisfy the hypothesis (4) of Lemma 1 with the conditions (1C) and (HE). Suppose also that

1. the pairs $(A, S)$ and $(B, T)$ satisfy the $\left(C L R_{S T}\right)$ property,

2. there exists $\phi \in \Phi$ such that

$$
d(A x, B y) \leq \phi(a L(x, y)+(1-a) M(x, y)),
$$

where

$$
\begin{aligned}
L(x, y) & =\max \{d(S x, T y), d(S x, B y), d(B y, T y)\} \\
M(x, y) & =\left(\max \left\{\begin{array}{c}
d^{2}(S x, T y), d(S x, B y) d(B y, T y) \\
d(S x, T y) d(S x, B y), \\
d(S x, T y) d(B y, T y), d^{2}(B y, T y)
\end{array}\right\}\right)^{\prime}
\end{aligned}
$$

for all $x, y \in X, 0 \leq a \leq 1$. Then, both pairs $(A, S)$ and $(B, T)$ have a coincidence point. Furthermore, if the pairs $(A, S)$ and $(B, T)$ are weakly compatible, then the selfmappings $A, B, S, T$ have a unique common fixed point.

By suitable choice of self-mappings, we derived the following. 
Corollary 4. Suppose that $(X, d)$ is a symmetric space and self-mappings $A, B, S, T$ on $X$ satisfy the hypothesis (4) of Lemma 1 with (1C) and (HE). Suppose that

1. the pair $(A, S)$ enjoys the $\left(C L R_{S}\right)$ property,

2. there exists $\phi \in \Phi$ such that

$$
\int_{0}^{d(A x, A y)} \varphi(t) d t \leq \phi\left(\int_{0}^{a L(x, y)+(1-a) M(x, y)} \varphi(t) d t\right)
$$

where $\varphi \in \Lambda$ and

$$
\begin{aligned}
L(x, y) & =\max \{d(S x, S y), d(S x, A y), d(A y, S y)\} \\
M(x, y) & =\left(\max \left\{\begin{array}{c}
d^{2}(S x, S y), d(S x, A y) d(A y, S y) \\
d(S x, S y) d(S x, A y), \\
d(S x, S y) d(A y, S y), d^{2}(A y, S y)
\end{array}\right\}\right)^{\prime}
\end{aligned}
$$

for all $x, y \in X, 0 \leq a \leq 1$. Then $(A, S)$ has a coincidence point each. Moreover, $A$ and $S$ have a unique common fixed point provided the pair $(A, S)$ is weakly compatible.

We present the following result as an application of Theorem 1.

Theorem 2. Suppose that $(X, d)$ is a symmetric space and families of self-mappings $\left\{A_{i}\right\}_{i=1}^{m},\left\{B_{j}\right\}_{r=1}^{n},\left\{S_{k}\right\}_{k=1}^{p}$ and $\left\{T_{l}\right\}_{l=1}^{q}$ on X with $A=A_{1} A_{2} \ldots A_{m}, B=B_{1} B_{2} \ldots B_{n}$, $S=S_{1} S_{2} \ldots S_{p}$ and $T=T_{1} T_{2} \ldots T_{q}$ satisfy the conditions (1C), (HE) and also (2.2)(2.1). Suppose that the pairs $(A, S)$ and $(B, T)$ satisfy the $\left(C L R_{S T}\right)$ property, then both of the pairs $(A, S)$ and $(B, T)$ have a coincidence point.

Moreover $\left\{A_{i}\right\}_{i=1}^{m},\left\{B_{j}\right\}_{j=1}^{n},\left\{S_{k}\right\}_{k=1}^{p}$ and $\left\{T_{l}\right\}_{l=1}^{q}$ have a unique common fixed point if the families $\left(\left\{A_{i}\right\},\left\{S_{k}\right\}\right)$ and $\left(\left\{B_{r}\right\},\left\{T_{h}\right\}\right)$ commute pairwise wherein $i \in\{1,2, \ldots, m\}, k \in\{1,2, \ldots, p\}, j \in\{1,2, \ldots, n\}$ and $l \in\{1,2, \ldots, q\}$.

Proof. The proof can be treated by following the lines in [20]

Now, we indicate that Theorem 2 can be used to derive common fixed point theorems for any finite number of mappings. As a sample for five mappings, we can derive the following by setting one family of two members while the remaining three of single members:

Corollary 5. Suppose that $(X, d)$ is a symmetric space and self-mappings $A, B, S, R, T$ on $X$ satisfy the hypothesis (4) of Lemma 1 with the conditions (1C) and (HE). Suppose also that

1. the pairs $(A, S R)$ and $(B, T)$ satisfy the $\left(C L R_{(S R)(T)}\right)$ property,

2. there exists $\phi \in \Phi$ such that

$$
\int_{0}^{d(A x, B y)} \varphi(t) d t \leq \phi\left(\int_{0}^{a L(x, y)+(1-a) M(x, y)} \varphi(t) d t\right),
$$


where $\varphi \in \Lambda$ and

$$
\begin{aligned}
L(x, y) & =\max \{d(S R x, T y), d(S R x, B y), d(B y, T y)\} \\
M(x, y) & =\left(\max \left\{\begin{array}{c}
d^{2}(S R x, T y), d(S R x, B y) d(B y, T y) \\
d(S R x, T y) d(S R x, B y), \\
d(S R x, T y) d(B y, T y), d^{2}(B y, T y)
\end{array}\right\}\right)^{\prime},
\end{aligned}
$$

for all $x, y \in X, 0 \leq a \leq 1$. Then, the pairs $(A, S R)$ and $(B, T)$ have a coincidence point. Furthermore, the self-mapings $A, B, R, S, T$ have a unique common fixed point if $(A, S R)$ and $(B, T)$ commute pairwise, that is, $A S=S A, A R=R A, S R=R S$, $B T=T B$.

Similarly, we can derive a common fixed point theorem for six mappings by setting two families of two members while the rest two of single members:

Corollary 6. Let $A, B, H, R, S$ and $T$ be self mappings of a symmetric (semi-metric) space $(X, d)$ satisfying $(1 C)$ and $(H E)$. Suppose that

1. the pairs $(A, S R)$ and $(B, T H)$ share the $\left(C L R_{(S R)(T H)}\right)$ property,

2. there exists $\phi \in \Phi$ such that

$$
\int_{0}^{d(A x, B y)} \varphi(t) d t \leq \phi\left(\int_{0}^{a L(x, y)+(1-a) M(x, y)} \varphi(t) d t\right)
$$

where $\varphi \in \Lambda$ and

$$
\begin{aligned}
L(x, y) & =\max \{d(S R x, T H y), d(S R x, B y), d(B y, T H y)\} \\
M(x, y) & =\left(\max \left\{\begin{array}{c}
d^{2}(S R x, T H y), d(S R x, B y) d(B y, T H y) \\
d(S R x, T H y) d(S R x, B y), \\
d(S R x, T H y) d(B y, T H y), d^{2}(B y, T H y)
\end{array}\right\}\right)^{\prime},
\end{aligned}
$$

for all $x, y \in X, 0 \leq a \leq 1$. Then, both of the pairs $(A, S R)$ and $(B, T H)$ have a points of coincidence. Furthermore, the self-mappings $A, B, H, R, S$ and Thave a unique common fixed point if both of the pairs $(A, S R)$ and $(B, T H)$ commute pairwise, that is, $A S=S A, A R=R A, S R=R S, B T=T B, B H=H B$ and $T H=H T$.

By setting $A_{1}=A_{2}=\ldots=A_{m}=A, B_{1}=B_{2}=\ldots=B_{n}=B, S_{1}=S_{2}=$ $\ldots=S_{p}=S$ and $T_{1}=T_{2}=\ldots=T_{q}=T$ in Theorem 2, we deduce the following:

Corollary 7. Suppose that $(X, d)$ is a symmetric space and self-mappings $A, B, S, T$ on $X$ satisfy the hypothesis (4) of Lemma 1 with the conditions (1C) and (HE). Suppose also that

1. the pairs $\left(A^{m}, S^{p}\right)$ and $\left(B^{n}, T^{q}\right)$ share the $\left(C L R_{S^{p}, T^{q}}\right)$ property, 
2. there exists $\phi \in \Phi$ such that

$$
\int_{0}^{d\left(A^{m} x, B^{n} y\right)} \varphi(t) d t \leq \phi\left(\int_{0}^{a L(x, y)+(1-a) M(x, y)} \varphi(t) d t\right),
$$

where $\varphi \in \Lambda$ and

$$
\begin{aligned}
L(x, y) & =\max \left\{d\left(S^{p} x, T^{q} y\right), d\left(S^{p} x, B^{n} y\right), d\left(B^{n} y, T^{q} y\right)\right\} \\
M(x, y) & =\left(\max \left\{\begin{array}{c}
d^{2}\left(S^{p} x, T^{q} y\right), d\left(S^{p} x, B^{n} y\right) d\left(B^{n} y, T^{q} y\right), \\
d\left(S^{p} x, T^{q} y\right) d\left(S^{p} x, B^{n} y\right), \\
d\left(S^{p} x, T^{q} y\right) d\left(B^{n} y, T^{q} y\right), d^{2}\left(B^{n} y, T^{q} y\right)
\end{array}\right\}\right)^{\frac{1}{2}},
\end{aligned}
$$

for all $x, y \in X, m, n, p, q$ are fixed positive integers. If $A S=S A$ and $B T=T B$, then the self-mappings $A, B, S, T$ have a unique common fixed point.

Remark 2. Corollary 7 is a weaker generalization of Theorem 1 as the commutativity requirements (that is, $A S=S A$ and $B T=T B$ ) in this corollary are relatively stronger as compared to weak compatibility in Theorem 1.

\section{Acknowledgement}

The authors would like to thank Professor M. Imdad for the reprint of his valuable paper [Common fixed point theorems in symmetric spaces employing a new implicit function and common property (E.A). Bull. Belg. Math. Soc. Simon Stevin 16, 421-433 (2009)].

\section{References}

[1] Aamri, M., Moutawakil, D.El: Some new common fixed point theorems under strict contractive conditions. J. Math. Anal. Appl. 270(1), 181-188 (2002) MR1911759 (2003d:54057)

[2] Aamri, M., Moutawakil, D.El: Common fixed points under contractive conditions in symmetric spaces. Applied Mathematics E-notes 3, 156-162 (2003)

[3] Abbas, M., Khan, A.R.: Common fixed points of generalized contractive hybrid pairs in symmetric spaces. Fixed Point Theory Appl. Article ID 869407, 11 pages (2009)

[4] Aliouche, A.: A common fixed point theorem for weakly compatible mappings in symmetric spaces satisfying a contractive condition of integral type. J. Math. Anal. Appl. 322(2), 796-802 (2006) MR2250617 (2007c:47066)

[5] Altun, I., Turkoglu, D., Rhoades, B.E.: Fixed points of weakly compatible maps satisfying a general contractive condition of integral type. Fixed Point Theory Appl. Vol. 2007, Article ID 17301, 9 pp. (2007) doi:10.1155/2007/17301 
[6] S. Banach, Sur les opérations dans les ensembles abstraits et leur application aux équations intégrales, Fund. Math. 3 (1922) 133-181.

[7] Bari, C.Di, Vetro, C.: Common fixed point theorems for weakly compatible maps satisfying a general contractive condition. Int. J. Math. Math. Sci. 2008, Art. ID 891375, 8 pp. (2008) MR2448276 (2009g:54091)

[8] Boyd, D.W., Wong, J.S.W.: On nonlinear contractions. Proc. Amer. Math. Soc. 20, 458-464 (1969)

[9] Branciari, A.: A fixed point theorem for mappings satisfying a general contractive condition of integral type. Int. J. Math. Math. Sci. 29(9), 531-536 (2002) MR1900344 (2003c:54075)

[10] Bukatin, M., Kopperman, R., Matthews, S., Pajoohesh, H.: Partial metric spaces. Amer. Math. Monthly 116, 708-718 (2009)

[11] Burke, D.K.: Cauchy sequences in semi-metric spaces. Proc. Amer. Math. Soc. 33, 161-164 (1972)

[12] Caristi, J.: Fixed point theorems for mapping satisfying inwardness conditions. Trans. Amer. Math. Soc. 215, 241-251 (1976)

[13] Chatterjea, S.K.: Fixed point theorems. C. R. Acad. Bulgare Sci. 25, 727-730 (1972)

[14] Chauhan, S., Aydi, H., Shatanawi, W. and Vetro, C.: Some integral type fixed-point theorems and an application to systems of functional equations. Vietnam J. Math. (2013) DOI 10.1007/s10013-013-0030-6

[15] Cho, S.H., Lee, G.Y., Bae, J.S.: On coincidence and fixed-point theorems in symmetric spaces. Fixed Point Theory Appl., Article ID 562130, 9 pages (2008)

[16] Galvin, F., Shore, S.D.: Completeness in semi-metric spaces, Pacific. J. Math. 113(1), 67-75 (1984)

[17] Gopal, D., Hasan, M., Imdad, M.: Absorbing pairs facilitating common fixed point theorems for Lipschitzian type mappings in symmetric spaces. Commun. Korean Math. Soc. 27(2) 385-397 (2012)

[18] Gopal, D., Imdad, M., Vetro, C.: Common fixed point theorems for mappings satisfying common property (E.A.) in symmetric spaces. Filomat 25(2), 59-78 (2011)

[19] Hicks, T.L., Rhoades, B.E.: Fixed point theory in symmetric spaces with applications to probabilistic spaces. Nonlinear Analysis 36, 331-344 (1999)

[20] Imdad, M., Ali, J.: Common fixed point theorems in symmetric spaces employing a new implicit function and common property (E.A). Bull. Belg. Math. Soc. Simon Stevin 16, 421-433 (2009) 
[21] Imdad, M., Ali, J., Khan, L.: Coincidence and fixed points in symmetric spaces under strict contractions. J. Math. Anal. Appl. 320, 352-360 (2006)

[22] Imdad, M., Chauhan, S., Kadelburg, Z., Vetro, C.: Fixed point theorems for non-self mappings in symmetric spaces under $\varphi$-weak contractive conditions and an application to functional equations in dynamic programming. Appl. Math. Comput. 227, 469-479 (2014)

[23] Imdad, M., Ali, J., Tanveer, M.: Coincidence and common fixed point theorems for nonlinear contractions in Menger PM spaces. Chaos, Solitons \& Fractals 42(5), 3121-3129 (2009) MR2562820 (2010j:54064)

[24] Imdad, M., Chauhan, S., Kadelburg, Z.: Fixed point theorems for mappings with common limit range property satisfying generalized $(\psi, \varphi)$-weak contractive conditions. Math. Sci. 2013, 7:16.

[25] Imdad, M., Pant, B.D., Chauhan, S.: Fixed point theorems in Menger spaces using the $\left(C L R_{S T}\right)$ property and applications. J. Nonlinear Anal. Optim. 3(2), 225-237 (2012)

[26] Imdad, M., Sharma, A., Chauhan, S.: Unifying a multitude of common fixed point theorems in symmetric spaces. Filomat (2014), in press.

[27] Imdad, M., Soliman, A.H.: Some common fixed point theorems for a pair of tangential mappings in symmetric spaces. Appl. Math. Lett. 23(4), 351-355 (2010)

[28] Jungck, G.: Commuting mappings and fixed point. Amer. Math. Monthly 83, 261-263 (1976)

[29] Jungck, G.: Compatible mappings and common fixed points. Internat. J. Math. Math. Sci. 9(4), 771-779 (1986) MR0870534 (87m:54122)

[30] Jungck, G.: Common fixed points for noncontinuous nonself maps on nonmetric spaces. Far East J. Math. Sci. 4(2), 199-215 (1996)

[31] Karapınar, E.: Generalizations of Caristi Kirk's theorem on partial metric spaces. Fixed Point Theory Appl. 2011:4, (2011) DOI:10.1186/1687-18122011-4

[32] Karapınar, E.: Some nonunique fixed point theorems of Ćirić type on cone metric spaces. Abstr. Appl. Anal. Vol. 2010, Article ID 123094, 14 pages (2010) DOI:10.1155/2010/123094

[33] Karapınar, E.: Fixed point theorems in cone Banach spaces, Fixed Point Theory Appl. 2009, Article ID 609281, 9 pages (2009)

[34] Karapınar, E., Patel, D.K., Imdad, M., Gopal, D.: Some nonunique common fixed point theorems in symmetric spaces through $C L R_{S T}$ property. Internat. J. Math. Math. Sci. Article ID 753965, 8 pages (2013) DOI: $10.1155 / 2013 / 753965$ 
[35] Kramosil, I., Michálek, J.: Fuzzy metric and statistical metric spaces. Kybernetika (Prague) 11(5), 336-344 (1975) MR0410633 (53 \#14381)

[36] Liu, Y., Wu, J., Li, Z.: Common fixed points of single-valued and multivalued maps. Int. J. Math. Math. Sci. 19, 3045-3055 (2005) MR2206083

[37] Liu, Z., Li, X., Kang, S.M., Cho, S.Y.: Fixed point theorems for mappings satisfying contractive conditions of integral type and applications. Fixed Point Theory Appl. 64, 18 pp. (2011)

[38] Menger, K.: Statistical metrics. Proc. Nat. Acad. Sci. (USA) 28, 535-537 (1942)

[39] Murthy, P.P.: Important tools and possible applications of metric fixed point theory. Proceedings of the Third World Congress of Nonlinear Analysts, Part 5 (Catania, 2000), Nonlinear Anal. 47(5), 3479-3490 (2001) MR1979244 (2004d:54038)

[40] Pant, R.P.: Noncompatible mappings and common fixed points. Soochow J. Math. 26(1), 29-35 (2000) MR1755133 (2000m:54048)

[41] Rhoades, B.E.: Two fixed-point theorems for mappings satisfying a general contractive condition of integral type. Int. J. Math. Math. Sci. 63, 4007-4013 (2003) MR2030391 (2005b:54074)

[42] Samet, B., Vetro, C.: An integral version of Ciric's fixed point theorem. Mediterr. J. Math. 9, 225-238 (2012)

[43] Sastry, K.P.R. and Krishna Murthy, I.S.R.: Common fixed points of two partially commuting tangential selfmaps on a metric space, J. Math. Anal. Appl. 250(2), 731-734 (2000)

[44] Sessa, S.: On a weak commutativity condition in fixed point considerations. Publ. Inst. Math. (Beograd) (N.S.) 34(46), 149-153 (1982)

[45] Singh, S.L., Tomar, A.: Weaker forms of commuting maps and existence of fixed points. J. Korean Soc. Math. Edu. Ser. B: Pure Appl. Math. 10(3), 145-161 (2003) MR2011365 (2004h:54039)

[46] Sintunavarat, W., Kumam, P.: Common fixed point theorems for a pair of weakly compatible mappings in fuzzy metric spaces. J. Appl. Math. Article ID 637958, 14 pages (2011) MR2822403

[47] Suzuki, T.: Meir-Keeler contractions of integral type are still Meir-Keeler contractions. Int. J. Math. Math. Sci. 2007 Art. ID 39281, 6 pages (2007) MR2285999 (2007k:54049)

[48] Tiwari, R., Shrivastava, S.K., Pathak, V.K.: A common fixed point theorem for weakly compatible mappings in symmetric spaces satisfying an integral type contractive condition. Hacet. J. Math. Stat. 39(2), 151-158 (2010) 
[49] Turkoglu, D., Altun, I.: A common fixed point theorem for weakly compatible mappings in symmetric spaces satisfying an implicit relation. Bol. Soc. Mat. Mexicana 13, 195-205 (2007)

[50] Vetro, C.: On Branciari's theorem for weakly compatible mappings. Appl. Math. Lett. 23(6), 700-705 (2010)

[51] Vijayaraju, P., Rhoades, B.E., Mohanraj, R.: A fixed point theorem for a pair of maps satisfying a general contractive condition of integral type. Internat. J. Math. Math. Sci. 15, 2359-2364 (2005) MR2184475 (2006g:54050)

[52] Wilson, W.A.: On semi-metric spaces. Amer. J. Math. 53, 361-373 (1931)

Near Nehru Training Centre,

H. No. 274, Nai Basti B-14,

Bijnor-246701, Uttar Pradesh, India.

email: sun.gkv@gmail.com

Department of Mathematics,

Atilim University, 06836, İncek, Ankara, Turkey.

Nonlinear Analysis and Applied Mathematics Research Group (NAAM),

King Abdulaziz University ,

Jeddah , Saudi Arabia.

email:erdalkarapinar@yahoo.com, ekarapinar@atilim.edu.tr 